important, given present controversies about the significance of pressuretemperature paths ${ }^{2,3}$ and uncertainties emerging over the interpretation of isotopic dating systems $\mathrm{s}^{3,4}$ in other high-grade terrains.

Most of the 'hot rocks' known as granulites are exposed as vast areas of the old shields of continents. Some, however, as at Fiordland, are fortuitously presented for inspection in younger mountain belts where their recent tectonic contexts can be readily evaluated and their tectonic significance better assessed. Many granulites, ancient and recent, preserve in their mineral assemblages, and often in delicate microscopic reaction textures, a detailed record of their pressure-temperature evolution that can be used to track their depth-temperature evolution with time, and therefore that of the crust.

Among the many possible post-peak metamorphic pressure-temperature paths are two end members: cooling without much change in crustal depth, otherwise labelled near-isobaric cooling (IBC); and exhumation or unroofing through significant crustal depths without much cooling, or near-isothermal decompression (ITD). Current thinking is that such ITD has to be rapid - on a timescale less than that of thermal relaxation by conduction. So fast exhumation mechanisms acting over sufficient timescales ( 10 million years) are invoked to explain ITD where it is clear that the history is indeed linked to a single metamorphic cycle. It is not surprising, then, that extensional collapse of thickened crust or continental extension accompanied by magmatism have become fashionable models for the formation and evolution of granulites.

Gibson and Ireland go further than simply relating a granulite metamorphism to rapid extension. They postulate that the Fiordland granulites may typify what the deeper and unexposed levels of an active extensional region such as the Basin and Range province of the United States might look like, at least in terms of the deformational structures and metamorphic grades. The extensional unroofing proposed for the Fiordland granulites is indeed similar to the exposure of core complexes; however, analogies with the Basin and Range extensional province should be viewed with some caution as the geometry of extension in the Fiordland case may differ from the possible geometries for the Basin and Range. The comparisons proposed by Gibson and Ireland should promote further structural and kinematic studies of granulite terrains that centre on the question of how extension is actually accommodated at such depths and temperatures.

Analysis of the thermal history of deep crustal rocks is not straightforward. Because of the high temperatures involved and a reliance on temperature-dependent isotopic systems ${ }^{4}$, it has seldom proved possible to define timescales of decompression precisely enough to show that the exhumation rates were necessarily more rapid than those that could be attained simply through erosion. Likewise, linking extensional deformational structures with the pressure-temperature history, and tying both to a well-defined time framework, has proved difficult for many older but important granulite terrains ${ }^{5}$. These older belts have often had complex histories, including the superposition of several unrelated events. Indeed, it has been argued by several workers that an ITD history deduced principally from metamorphic reaction textures may only be apparent - the result of partial overprinting of an earlier thermal event by a later, lower-pressure one, separated from the first by a considerable time $e^{2,3}$. Resolution of this problem clearly requires high-quality isotopic dating, and the Fiordland example shows it can be done, and conclusively.

Can most granulites be linked to rapid extension following previous thickening events, or does rifting alone account for granulite metamorphism? Is the core complex analogy proposed for Fiordland ${ }^{1}$ appropriate to other granulites in which extensional structures are observed? These are complex questions for which simple and general answers are not likely. High-grade metamorphic terrains not only preserve a variety of pressuretemperature histories, including the ITD and IBC styles, but also a range of apparent cooling and exhumation rates. For example, recent geochronology has shown that extensional unroofing of the deep granulites of the Grenville province was a slow process involving shear zones active for some 150 million years ${ }^{5}$. This slow exhumation contrasts with the rapid unroofing typical of core complexes ${ }^{6}$ and apparent in the Fiordland case ${ }^{1}$, and implies different tectonic processes controlling the post-granulite crustal evolution. The Fiordland study presented by Gibson and Ireland should be regarded as a stimulus for further studies of deep-crustal granulites, rather than a template for the interpretation of these important metamorphic terrains.

Simon L. Harley is in the Department of Geology and Geophysics, University of Edinburgh, West Mains Road, Edinburgh EH9 3JW, UK.

1. Gibson, G. M. \& Ireland, T. R. Nature $375,479-482$ (1995).

2. Hand, M. Dirks, P. G. H. M., Powell. R. \& Buick, I. S Geology 20, 649-652 (1992)

3. Hensen, B. J. \& Zhou, B. Geology 23, 225-228 (1995)

4. Mezger, K., Essene, E. J. \& Halliday, A. N. Earth planet. Sci. Lett. 113, 397-409 (1992)

5. Cosca. M. A., Essene, E. J., Mezger, K. \& van der Pluijm, B. A. Geology 23, 361-364 (1995)

6. Baldwin, S. L., Lister, G. S., Hill, E. J., Foster, D. A. \& McDougall, I. Tectonics 12.611-628(1993)

\section{Water everywhere}

EVERY cubic metre of air contains about $10 \mathrm{~g}$ of water. Shipwrecked mariners and desert dwellers, and householders resentful of the cost and contamination of their piped supply, might welcome a way of extracting it. Some chemical absorbents, such as silica gel and calcium chloride, extract water from the air very efficiently. This, however, merely generates a new problem: how to extract the water from the absorbent? Daedalus now has a cunning answer.

It is based on those 'super-slurper' polymers, widely used in nappies and bandages, which absorb hundreds of times their weight of water. They don't work by capillary action like a towel; they imbibe water chemi-osmotically and are plasticized by it. They can even take up water from the air, though current nappy formulations are designed to minimize this effect. Daedalus, however, wants to maximize it. DREADCO's chemists are working on a super-slurper to absorb vast amounts of water from the air. And how to extract the water from this new product? Easy, says Daedalus: you eat it.

Many super-slurpers are almost edible as it is. They are copolymers of corn starch with a certain amount of acrylic monomer. The DREADCO team are adding polymerizable amino acids to the recipe, seeking an edible and hygroscopic super-slurper. Just leave the product in the air - ideally overnight, to take up water vapour from the colder and more humid night air - and it will swell into a flabby gel containing up to $99 \%$ absorbed water. You can then have it for breakfast. Your digestion will break it down simply and safely. Its starch and amino acids will have some value as food; the acrylic residues will become healthy, inert fibre. But its main component, water, will simply be released in your stomach. In effect, it will be a solid drink.

'Drink Me', as the new product will be called, will be snapped up by explorers, sailors and tourists suspicious of the local water. About 10-20 g a day will save them from having to drink anything at all. Tea, coffee and orange flavours will be available. Drink Me could even be used for washing. Rolled over the skin, it would act rather like those sticky rollers which remove fluff from clothes.

Drink Me may compete in the slimming market, too. In its swollen state it will be the bulkiest, lowest-calorie food imaginable. Even better, a consumer who ate it dry, and then drank a hundred times as much water, would experience such a sudden massive bloating of the stomach that he would not want to eat anything else for some time.

David Jones 